\title{
Correlation between glycated hemoglobin HbA1c and serum lipid profile in patients with type 2 diabetes
}

\author{
Asmaa Alboueishi ${ }^{1}$, Yosra Lamami ${ }^{1}$ Huda Aldeeb ${ }^{1}$, Mohammed Dali2 , Fawzi Omar $^{1 *}$ \\ 1 Cell Biology Research Group, Human Tissue Culture Department, Biotechnology Research Center, Tripoli, \\ Libya \\ 2AloomalahiaCompany for Medical Diagnostic (Exclusive Agent for Bioscientia Laboratories Germany) Tripoli, \\ Libya
}

\begin{abstract}
Background: Hyperlipidemia is a common risk factor for diabetes that leads to cardiovascular disease, one of the causes of death of diabetic patients. Theaimof this study was to investigate the association between $\mathrm{HbA1c}$ levels and serum lipids in Libyan patients withtype 2 diabetes. Material and methods: The study was conducted in 2019 on 325 patients (174 males, 151 females) with type 2 diabetes referred to a private clinical laboratory in Tripoli, Libya. Blood samples were collected for measurement of $\mathrm{HbA1c}$, fasting blood glucose and serum lipid concentrations. Diabetes was defined according to the American Diabetes Association criteria.The data were analyzed using an independent t-test and Pearson'scorrelation test.Results: The ages of the patients ranged from 40 to 83 years, with a mean of $51.52 \pm 14.32$ years SD. No significant correlation between $\mathrm{HbA1c}$ and age was noted $(\mathrm{r}=0.011, \mathrm{p}=0.063)$. There was a significant positive correlation betweenHbA1c level and fasting blood glucose $(\mathrm{r}=0.641, \mathrm{p}=0.000)$, low-density lipoprotein $(\mathrm{r}=0.240, \mathrm{p}=0.000)$, total cholesterol $(\mathrm{r}=$ $0.223, \mathrm{p}=0.000)$ and triglycerides $(\mathrm{r}=0.140, \mathrm{p}=0.067)$. The correlation between HbA1c and high-density lipoprotein- $C$ was negative but not significant $(r=-0.088, p=0.123)$. Conclusion: HbA1c could be used as a predictor of dyslipidemia and thus it may serve as anindicator of the development of cardiovascular disease in patients with type-2 diabetes mellitus.
\end{abstract}

Keywords: HbA1c, lipid profile, LDL cholesterol, HDL cholesterol, fasting blood sugar, type 2 diabetes, dyslipidemia

CitationAlboesh Ai,omar Libyan F.Correlation between glycated hemoglobin $\mathrm{HbA1C}$ and serum lipid profile in patients with type 2 diabetes2021;15(2):14-18.Libya J Med Res.https://doi.org/10.54361/ljmr.15204

Received: 06/09/21; accepted: 14/09/21; published: 31/12/21

Copyright (CLibyan Journal of Medical Research (LJMR) 2021. Open Access. Some rights reserved. This work is available under the CC BY license https://creativecommons.org/licenses/by-nc-sa/3.0/igo

\section{INTRODUCTION}

on health, quality of life, and healthcare systems. According to the International Diabetes Federation, 463 million adults are currently living with diabetes. Without effective intervention, about 578 million people will have diabetes by 2030and thenumber will jump to 700 million by 2045.The proportion of
Diabetes mellitus(T2DM) is a chronic endocrinedisorder [1]. Itis characterized by abnormal insulin secretion due to peripheral resistance and accounts for $85-90 \%$ of all people with diabetes [2].

T2DM is a rapidly growing public health problem worldwide, with a significant impact 
In a study on the association of $\mathrm{HbA1c}$ with the serum lipid profile, it was suggested that the level of $\mathrm{HbAlc}$ could predict the developmentof dyslipidemia in patients with DM (8). Apart from the classical risk factors for cardiovascular disease (CVD) such as dyslipidemia, elevated $\mathrm{HbA1c}$ seems to be another independent risk factor. It is estimated that there is an $18 \%$ increased risk of CVD for each $1 \%$ rise in absolute $\mathrm{HbA1c}$ level inthe diabetic population. This positive correlation between $\mathrm{HbA} 1 \mathrm{c}$ and CVD has been demonstratedalso in non-diabeticpeople, even within the normal range of $\mathrm{HbA1c}$. [9]

The aim of this study was to evaluate the correlation between $\mathrm{HbA} 1 \mathrm{c}$ and serumlipid profile in patients with T2DM as well as to evaluate the importance of $\mathrm{HbA1c}$ as an indicator of dyslipidemia.

\section{MATERIALS AND METHODS:}

Blood samples were drawn with a sterile syringe and placed in sterile tubes after 12-14 hours of overnight fasting. The samples were centrifuged at $3000 \mathrm{rpm}$ for 10 minutes and serum was stored at $4^{\circ} \mathrm{C}$. FBS and serum lipids were measured by enzymatic methodsbyusinga Roche/ Hitachi 912/ modular analyzer: CAN 435, Germany). $\mathrm{HbA1c}$ was measured by an immunoturbidimetric assay on a BT PLUS Auto analyzer.

The National Cholesterol Education Program criteria (NCEP/ATP III) for the diagnosis of the metabolic syndrome were used[10]. According to these criteria, hypercholesterolemia is defined as TC $>200$ $\mathrm{mg} / \mathrm{dl}$, high LDL-C when the value $>100$ mg/dl,hypertriglyceridemia when TG > $150 \mathrm{mg} / \mathrm{dl}$, and low HDL-C as $<40 \mathrm{mg} / \mathrm{dl}(10)$.

\section{STATISTICAL ANALYSIS}

test for independent samples (two tailed) was used to compare mean values. $P$ values $<0.01$ were accepted as significant. The value of $\mathrm{HbA1c}$ is given as a percentage of the people with $\mathrm{T} 2 \mathrm{DM}$ is increasing in most countries(3). Nearly $80 \%$ of people with T2DM live in low and middle-incomecountries. [4]

It has been estimated that about 37 million people in the Middle East and North Africa region are living with T2DM [5]. Moreover, this region had the highest age-adjusted prevalence of diabetes in adults in 2019 $(12.2 \%)$, and this percentage is expected to increase to $13.3 \%$ by 2030 (3). However, there is very little information on diabetes in Libya.

One of the most common complications linked with uncontrolled hyperglycemia is dyslipidemia.Hence, T2DM patients are prone to diabetic dyslipidemia, which puts them at risk of developing macrovasculardiseases (stroke, peripheral vascular disease and coronary artery disease) and microvasculardiseases (nephropathy, neuropathy and retinopathy) $[6,7]$.

This cross-sectional study was performedat the AloomalahiaMedical Laboratory in Tripoli, Libya on all T2DM patients with an active record at the laboratory who were referred to the

Laboratory between January and December 2019(Ethical approval was obtained from the Ethics committee of biotechnology research center).

Patients with type 1 diabetes, gestational diabetes or prednisolone-induced diabetes were excluded from the study, which was conducted on 325 patients.

Whole blood and sera samples were analyzed for fasting blood sugar (FBS), HbA1c, total cholesterol (TC), triglycerides (TG), highdensity lipoprotein cholesterol (HDL-C) and low-density lipoprotein cholesterol (LDL-C).

The data were analyzedbythe SPSS statistical package version 27.0. Pearson's correlation test was used to examine the correlations between $\mathrm{HbA1c}$ and the other parameters. Student's t- 
expressed as mean \pm standard deviation (SD)

\section{RESULTS AND DISCUSSION}

Significant, positive correlation between $\mathrm{HbA1c}$ and FBS ( $r=0.0641, \mathrm{p}=0.000$ ), which is Consistent with another Libyan study (11)showing a highly significant direct correlation

Between FBS and HbA1c.A study in Saudi Arabiaalso showed similar results [12], and Several Studies indicate that $\mathrm{HbA1c}$ may be useful as a diagnostic test for diabetes such Metcalf

Et al(13).

$\mathrm{HbA1c}$ had a significant direct relationship with total cholesterol $\left(\mathrm{r}=0.223, \mathrm{p}=0.000^{* *}\right)$

Triglycerides and LDL $(r=0.104, p=0.67)(r=$ $\left.0.240, p=0.000^{* *}\right)$ but not with HDL

$(\mathrm{r}=0.88, \mathrm{p}=0.123)$. In a study by Ghari Arab and Alireza, $\mathrm{HbA1c}$ had a significant

Positive Correlation with total cholesterol, triglycerides, and LDL and HDL levels [14],

These results suggest that the relationship between $\mathrm{HbA} 1 \mathrm{c}$ level and serum lipids of patients

With type 2 diabetes might be a useful predictor of CVD in these patients [15].

In Oman, Al-Alawi reported a correlation between improved dyslipidemia and $\mathrm{HbA} 1 \mathrm{c}$

Control (16) As Hyperlipidemia has been associated with the development of CVD,

Dyslipidemia isLikely to be but one of many reasons for the accelerated macro vascular

Disease in diabeticPatients. Nonetheless, treatment of lipid abnormalities has the potential to

Reduce cardiovascular events more than 50\%, to rates that are seen in countries with lower Cholesterol and less atherosclerotic burden. This leads to the expectation that treatment of Elevated lipid levels will allow patients with diabetes to lead longer healthier lives.[17]. Our resultsindicate ThatHbA1c level might be a useful predictor of CVD in patients with (Table 2 and figure 1 ). totalhemoglobin and values of all other parameters are given in $\mathrm{mg} / \mathrm{dl}$. All values are

A total of 325patients with T2DM (151 men and 174 women) were included in this study. The mean ages \pm SD of the male and female patients, respectively, were $54.0 \pm 14.09$ years and $48.6 \pm 14.07$ years SD.The mean level of $\mathrm{HbA} 1$ cwas $8.5 \% \pm 7.9 \% \mathrm{SD}$, which indicates inadequate glucose control (Table 1). Astudy in Iran [14] and another in Afghanistan (8) both reported higher mean $\mathrm{HbA1c}$ levels( $8.83 \%$ and $9.19 \%$, respectively).

The mean valuesofFBS, TC,TG,HDL-C and LDL-C(176.82, 188.53, 157.31,38.99 and $150.0 \mathrm{mg} / \mathrm{dl}$, respectively) were higher in T2DMpatients than the reference normal range (NCEP ATPIIIguidelines),indicating dyslipidemiaand inadequate glycemic control (Table 1).

The association of T2DM with CVD is wellestablished.Moreover, both lipid profile and DM have been shown to be important predictors of metabolic disorders, includingdyslipidemia, hypertension, hyperinsulinemia, and CVD [17].

People with T2DM have higher cardiovascular morbidity and mortalityandaredisproportionately affected by CVD compared topeople without DM. Early detection and treatment of dyslipidemia associated with DM may be one-stepto reducing the CVD risk(9).HbA1c could be used as a predictor of dyslipidemia, and early diagnosis of dyslipidemia can be used to initiate preventive measure against the development of vascular complications in T2DM. In this work, a positive correlation was observed between $\mathrm{HbA} 1 \mathrm{c}$ and $\mathrm{TC}(\mathrm{p}=$ 0.0001)(Figure 1).

In this study, age and $\mathrm{HbA} 1 \mathrm{c}$ were not significantly correlated $(r=0.011, P=0.063)$.

These

Findings are consistent with a previous studyinPakistan[4]. On the other hand, there was a 


\section{CONCLUSION}

biomarker would facilitateearly diagnosis of dyslipidemiaby using a relatively inexpensive blood test that is commonly used for the assessment of glycemic control.Screening high-risk T2DM patients would enable timely intervention with lipid-lowering drugs.
$\mathrm{HbA1c}$ was significantly and positivity associated with the levels of the commonly analyzed serum lipids. This points to the possibility of using $\mathrm{HbA} 1 \mathrm{c}$ not only for the assessment of glycemic control, but also as a potential biomarker for predicting dyslipidemia in patients with T2DM. Such a

\section{Acknowledgment:}

We thank Dr. Hajer M. Almouaketforstatistical analysis.

\section{Conflict of interest:}

The authors declare that there are no conflicts of interest.

\section{Funding:}

This work was supported by the Biotechnology Research Center, Tripoli, Libya.

\section{Author contributions:}

AsmaaAlboueishi,Fawzi Omar: conceived the study. Yosraelammami,HudaAldeeb, Mohammed Dali: collected data. Both authors participated in data analysis, manuscript writing and review, and approval of final version.

\section{References:}

DiabetesAtlas.6thed.http://www.idf.org/sites/ default/files/attachments

/MENA\%20factsheet.pdf (2014, accessed 25 August 2016).

6. Kundu, D., Saikia, M., \& Paul, T. (2017). Study of the correlation between total lipid profile and glycosylated hemoglobin among the indigenous population of Guwahati. Int J Life SciScienti Res, 3(4), 1175-1180.

7. Naqvi, Syeda, et al. (2017) "Correlation between glycated hemoglobin and triglyceride level intype 2 diabetes mellitus." Cureus9.6 (2017).

8. Hussain, Arshad, et al. (2017) "Correlation between hemoglobin A1c and serum lipid profile inAfghani patients with type 2 diabetes: hemoglobin A1c prognosticates

dyslipidemia." Therapeutic advances in endocrinology and metabolism 8.4 (2017): 557.

9. Khaw, Kay-Tee, et al. (2004) "Association of hemoglobin A1c with
1. American Diabetes Association (2012). Standards of medical care in diabetes-2012. Diabetes care, 35 Supply 1(Suppl 1), S11-S63.

2. World Health Organization. "DiabetesFactsheet ( 2012) " Available from: World

HealthOrganization, Web site: http://www. Who. Int/media Centre/factsheets/fs312/en (accessed 2015 Sep 14) (2016).

3. Atlas, IDF Diabetes. 'International Diabetes Federation 7th Edition,( 2015)." (2016).

4. Tabish SA. (2007) Is Diabetes becoming the biggest epidemic of the twenty first century ? Int $f$ Health sci2007; $1: V-$ VIII

5. International Diabetes Federation. Middle East and North Africa at a glance.IDF 
diabetic adults at baseline. J. Diabetes. Complic.2017.

14. Ghari Arab, Alireza, et al. (2018) "Correlation between Hemoglobin A1c and Serum Lipid Profile in Type 2 Diabetic Patients Referred to the Diabetes Clinic in Gorgan, Iran." Journal of Clinical and Basic Research 2.1 (2018): 26-31.

15. Naeem,Muhammad, etal. "The role of. The role of glycated hemoglobin (HbA1C) and serum lipid profile measurements to detect cardiovascular disease in type 2 diabetic patients.Hemoglobin ( $\mathrm{HbA} 1 \mathrm{c})$ and serum lipid profile measurements to detect cardiovascular diseasesIn type 2 diabetic patients." South East Asia Journal of Public Health 5.2 (2015) 3034.

16. Al-Alawi SA. (2014) Serum lipid profile and glycated hemoglobin status in Omani patientsWith type2 diabetes mellitus attending a primary care polyclinic.

Biomedical

Research2014:25(2).

17. Goldberg, Ira J. (2001) "Diabetic dyslipidemia: causes and consequences." The Journal of Clinical Endocrinology \& Metabolism 86.3 (2001): 965-971. cardiovascular disease andmortality in adults: the European prospective investigation into cancer in Norfolk." Annals of internal medicine 141.6 (2004): 413-420.

10. National Cholesterol Education Program (US) (2002). Expert Panel on Detection, and Treatmentof High Blood Cholesterol in Adults. Third report of the National Cholesterol EducationProgram (NCEP) Expert Panel on detection, evaluation, and treatment of high bloodcholesterol in adults (Adult Treatment Panel III). No. 2. The Program, 2002.

11. Aghil, O. A., Zwawi, A. A., Masoud, B. B., Alsharif, F. A., \&Elhegagi, A. M. (2017) Correlationbetween Glycated Hemoglobin Levels with, Serum Glucose and Serum Lipid Levels in Type-IIDiabetes Mellitus in Libyan Kuwait Med J.2017; 49 :135.

12. Alouffi, S., Saeed, M., Alharbi, M., Saaed, A., Ahmad, S., \&Hassanto, R. (2017) The Relationship Between Hba1c And Lipid Profile In Type 2 Diabetic Saudi Patients .Biochem. Cell.Arch. Vol. 17, No. 1, pp. 243-248, 2017.

13. Metcalf $\mathrm{P}$ et al (2017) $\mathrm{HbA1c}$ in relation to incident diabetes and diabetesrelated complications in non- 


\section{Tables}

Table 1: Means of Glycated hemoglobin, fasting blood Glucose and serum lipids in patients with type 2 diabetes mellitus

\begin{tabular}{lllll}
\hline Parameters & Mean & SD & Range & Normal range \\
\hline HbA1c $(\%)$ & 8.05 & 7.9 & $5.50-16.50$ & Less than 6.5 \\
FBS $(\mathrm{mg} / \mathrm{dl})$ & 167.82 & 82.66 & $95-580$ & $75-120$ \\
TC $(\mathrm{mg} / \mathrm{dl})$ & 188.53 & 76.66 & $96-321$ & $\leq 200$ \\
TG $(\mathrm{mg} / \mathrm{dl})$ & 157.31 & 118.5 & 45.779 & $>150$ \\
HDL-C (mg/dl) & 38.99 & 24.20 & $18-98$ & $<40$ \\
LDL-C (mg/dl) & 150.0 & 17.12 & $23-256$ & $\leq 100$ \\
\hline
\end{tabular}

Table 2. Correlation of hemoglobin levels with age, fasting blood Glucose and serum lipids in patients with type 2 diabetes mellitus

\begin{tabular}{lll}
\hline Parameters & Pearson correlation & P value \\
\hline Age & 0.011 & 0.063 \\
FBS & 0.641 & $0.000^{*}$ \\
TC & 0.223 & $0.000^{* *}$ \\
TG & 0.104 & $0.67^{*}$ \\
HDL-C & -0.88 & 0.123 \\
LDL-C & 0.240 & $0.000^{* *}$ \\
\hline
\end{tabular}

*Statistically significant 


\section{Figure legend}

Fig. 1: Correlation of hemoglobinwith age, fasting blood glucose and lipid profile components in adult patients with type 2 diabetes mellitus.HbA1c (percent) is on y-axis.
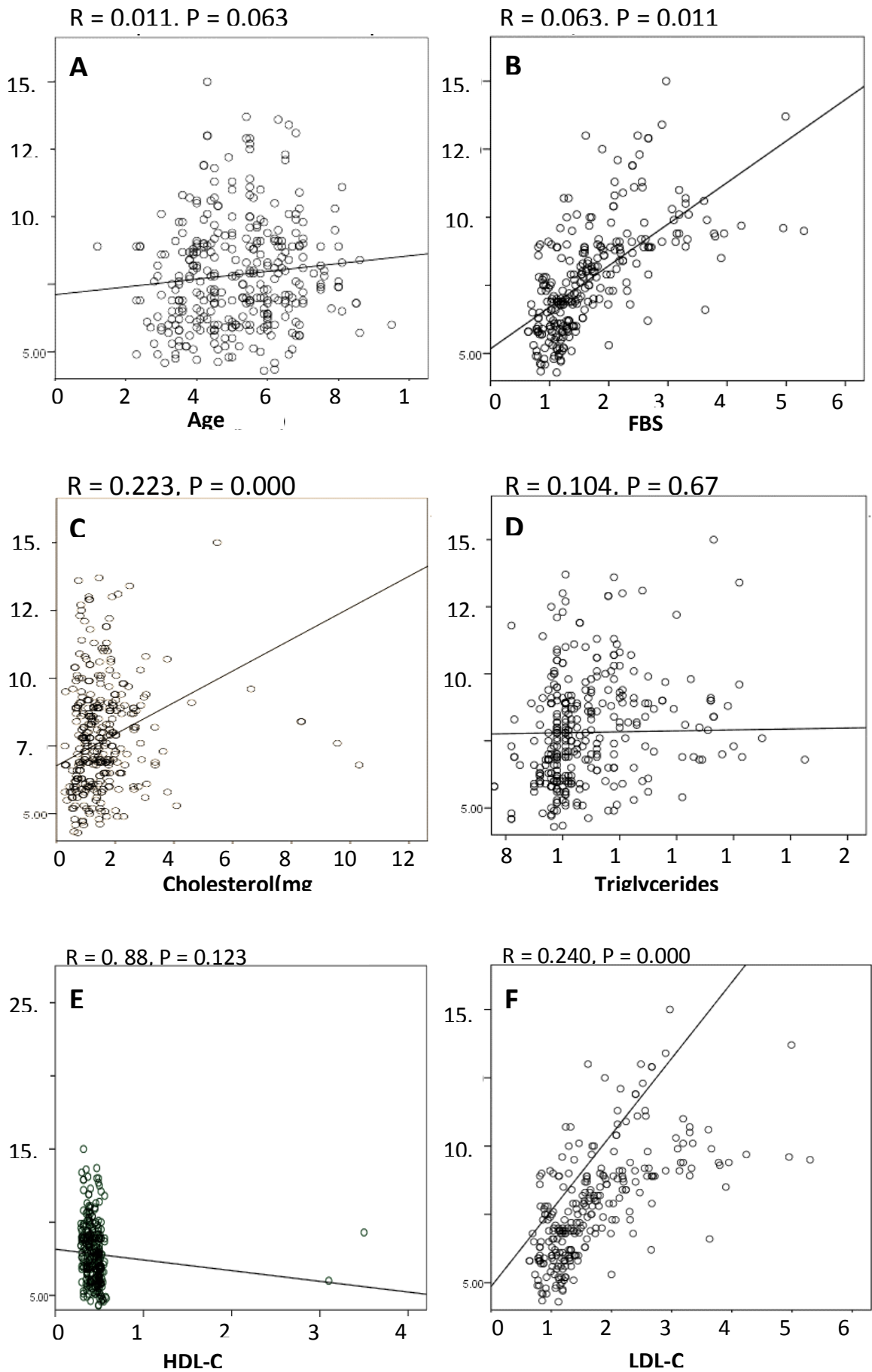